\title{
Yaşlılıkta Sosyal İzolasyon ve Yalnızlık ${ }^{1}$
}

\author{
DOI: $10.26466 /$ opus.648658
}

$*$

\author{
Ebru Akbaş * - Gülay Taşdemir Yiğitoğlu ** - Nesrin Çunkuş *** \\ * Doktora Öğr., Pamukkale Üniversitesi Sağlık Bilimleri Enstitüsü Hemşirelik ABD, Denizli \\ E-Posta: ebruakbas1981@hotmail.com ORCID: 0000-0002-9941-8436 \\ ** Dr. Öğr. Üyesi, Pamukkale Üni. Sağlık Bilimleri Fakültesi Hemşirelik Bölümü, Denizli/Türkiye \\ E-Posta: gyigitoglu@pau.edu.tr \\ ORCID: 0000-0002-8075-7155 \\ *** Doktora Öğr., Pamukkale Üniversitesi Sağlık Bilimleri Enstitüsü Hemşirelik ABD, Denizli \\ E-Posta: ncunkus@pau.edu.tr \\ ORCID: $\underline{0000-0003-1813-1511}$
}

\section{Öz}

Günümüzde yaşlllarn yalnızlık ve sosyal izolasyon sorunları giderek büyümektedir. Toplumsal yapıdaki hızlı değişimler yaşlının bu duruma uyum göstermesini zorlaştırmakta ve yaşlıda daha yoğun sosyal izolasyon ve yalnızlı duygusunun yaşanmasina neden olmaktadır. Yaşlı bireylerin yalnızlık duygusuna sebep olan faktörler; eş ya da arkadaş ölümü, emekli olma, evinden ayrlma, rollerde değişim, duyusal kayıplar, kronik hastalıklar, fiziksel stnırlliklar, sosyal destek sistemlerinin azlı̆̆ı, sosyokültürel koşullar, ekonomik güçlükler ve başkalarına bağıml olmadır. Yalnızlık duygusu yaşlının yaşamın olumsuz yönde etkileyerek bireyin yaşantısını dayanulmaz hale getirebilmektedir. Yapılan araştırmalarda kısıtlı ya da tatmin edici olmayan sosyal ilişkiler yaşayan yaşlılarda mortalite riskinin, güçlü sosyal ilişkileri olan yaşlllara göre daha yüksek olduğu belirtilmektedir. Böyle istenmeyen durumlarm önlenmesinde doyum sağlanabilen bir sosyal destek sistemi geliştirmek yaşlının yalnızlık hissini azaltarak daha iyi hissetmesini sağlayacaktır.

Yaşlı bireylerin sosyal izolasyon ve yalnızlı duygularmı literatür doğrultusunda ifade etmek ve sonuçlarını değerlendirmek derlemenin amacıdır. Yapılacak multidisipliner çalışmalarda yaşlı sorunlarımın çözümüne ışık tutabilecek bir yazı olduğu düşünülmektedir.

Anahtar Kelimeler: sosyal izolasyon, yaşll, yaşlılık, yalnızlık

\footnotetext{
${ }^{1}$ Bu çalışma, 25-27 Nisan 2019 Denizli'de 10. Ulusal Yaşlılık Kongresi'nde sözel bildiri olarak sunulmuştur.
} 


\title{
Social Isolation and Loneliness in Elderly
}

\begin{abstract}
Loneliness and social isolation issue in elderly becomes a bigger problem every day. Rapid changes in social construction makes it harder for elderly to adapt, causes them to experience social isolation and loneliness more intensely. Causes for loneliness in elderly are; loss of spouse or a friend, retirement, leaving home, changes in roles, loss of senses, chronic diseases, physical restraints, lack of social support system, socio-cultural conditions, financial hardships and dependence on others. Loneliness affects elder's life satisfaction negatively and sometimes even makes living unbearable for them. Research conducted in this area have shown that mortality risk of elders who have limited or non-satisfactory social relations is higher than those who have strong social relations. To prevent undesired outcomes, developing a social support system where elderly feels satisfied with, may help elderly to feel less lonely and feel happier. This review aims to represent feelings social isolation and loneliness in line with the literature and evaluate their consequences. It is thought that this review may help multi-disciplinary research in solving issues of the elderly.
\end{abstract}

Keywords: social isolation, elder, elderly, loneliness 


\section{Giriş}

Günümüz dünyasında yaşam kalitesinin artması, tıbbi ve teknolojik gelişmeler, bulaşıcı hastalıkların azalması, kronik hastalıklarla yaşam süresinin uzaması ve ölüm oranlarının azalması ile yaşlı nüfus giderek artmaktadır (Santrock, 2015). Yaşlı nüfusu, dünya nüfusunun \%9.1'ini oluşturmaktadır. Türkiye'de ise son beş yılda yaşlı nüfusu \%16 artarak 7 milyonu aşmıştır (Türkiye İstatistik Kurumu, 2018). Bu artışla birlikte sosyal ve ekonomik anlamda bir çok problem yaşanmaktadır (Attanasio ve Pistaferri, 2016). Bu nedenle yaşl1lık süreci ile ilgili bir çok boyutun ele alınması önem taşımaktadır.

Yaşlılık, biyolojik, psikolojik, mental ve sosyal alanlarda çeşitli düzeylerde değişikliklerin yaşandığı bir dönemdir (Townsend, 2016). Vücudun işlevsellik kapasitesinde yaşanan azalma ve buna eşlik eden kronik hastalıkların varlığı yaşlının duygusal ve sosyal yönden başkalarına daha çok ihtiyaç duymasina neden olmaktadır (Beğer ve Yavuzer, 2012; Kislaya, Santos, ve Gil, 2013). Yaşlılığın ele alınıp incelendiği çalışmalarda yaşı bireyin yaşamdan aldığı doyumun azaldığı, yalnızlık ve sosyal izolasyon duygularının ise daha çok hissedildiği belirtilmektedir (Kaçan-Softa, Öztürk, Dindaş, ve Göçmen, 2015; Erol, Sezer, Şişman, ve Öztürk, 2016; Kapıkıran, 2016; Kalınkara ve Sarı, 2019).

Bu dönemde fizyolojik düzeyde yaşanan gerileme, üretim kapasitesinde azalma, emekli olma, kronik hastalıkların varlığı, huzurevinde kalma gibi bir takım faktörler maddi ve manevi alanda sıkıntı oluşturmaktadır. Yaşlılıkta her alanda yaşanılan hızlı değişim, sosyal yapıyı da etkileyerek yaşlıların fiziksel, ruhsal, sosyal ve bilişsel birçok sorunla karşılaşmasına dolayısıyla yaşlılığın toplumsal bir sorun haline gelmesine neden olmaktadır (Danış, 2007; Kurt, Beyaztaş ve Erkol, 2010; Beğer ve Yavuzer, 2012). Bu durumda, yaşlı birey sözü dinlenilen bir otorite olarak görülmekten çıkıp, bir yük olarak görülmeye başlar. Toplumda konum olarak "bilge kişi”" olarak anılan yaşlı artık sosyal statüsünü kaybetmiş, merhamet duyulması gereken, güçsüz bir duruma düşmüştür (Danış, 2007; Kurt, 2008; Görgün Baran, 2016).

Aktif bir konumdan pasif bir konuma geçen, önceki rollerini yerine getiremeyen yaşlı birey, meslek hayatı, sosyal ve kültürel çevresinden uzaklaşarak yalnız ve izole bir yaşam sürmek zorunda kalmaktadır (Danış, 2007; Kurt, 2008). Günümüzde yaşlıların bireysel, fizyolojik, çevresel nedenlerden dolayı yalnızlık ve sosyal izolasyon sorunları giderek büyümektedir. Belirtilen bu sebeplerden ve toplumsal yapıdaki hızlı değişimler yaşlının bu duruma 
uyum göstermesini zorlaştırmakta ve yaşlıda daha yoğun sosyal izolasyon ve yalnızlık duygusunun yaşanmasına neden olmaktadır.

Yaşlılık döneminde meydana gelen fizyolojik değişiklikler, kronik hastalıklar, emeklilik ve eş kaybının yarattığı sorunlar, bunlara bağlı rol kayıpları, kentsel yaşam, yardımcı araç kullanımı, ekonomik kayıplar gibi durumlar bireyin kendini kabulünü zorlaştırmaya, sosyal ilişkilere girememeye, çekingen hissetmeye ve benlik saygısında düşmeye neden olmaktadır. Buna bağlı olarak yaşlı bireyin çevresindekilerle iletişimi bozulmakta ve yalnızlık duygusu daha fazla hissedilmektedir (Öz ve Svvift, 2002; Altuğ, Yağcl, Kitiş, Büker, ve Cavlak, 2009; Erol, Sezer, Şişman, ve Öztürk, 2016).

Bu derlemenin amacı yaşlı bireylerin sosyal izolasyon ve yalnızlık duygularını literatür doğrultusunda belirtmek ve sonuçlarını değerlendirmektir.

\section{Kavram Olarak Yalnızlık ve Sosyal İzolasyon}

Sosyal izolasyon genelde yalnızlık kelimesiyle eş anlamlı olarak kullanılan kavramlardır. Ancak her iki kavram birbirinden farklı anlamdadır.

Sosyal izolasyon "bireyin sosyal olarak ait olma hissini kaybettiği, diğer kişilerle bağlantı kuramadığı, çok az sosyal irtibatta bulunduğu ve bunların kaliteli bir ilişkiyi sağlamakta yetersiz olduğu" durum olarak tanımlanmaktadır (Olufemi, 2017).

Nanda Hemşirelik Tanıları El Kitabı sosyal izolasyonu; başkaları ile daha fazla birlikte olma gereksinimi, isteği olan, böyle algılayan, ancak ilişki kuramayan bir birey ya da gruptaki durum olarak tanımlamış ve yalnızlığa neden olan bir faktör olarak nitelendirmiştir (Carpenito, 2012).

Yalnızlık ise "sosyal ilişkilerdeki yoksunluk ve yetersizlikten kaynaklanan, bireyleri pek memnun etmeyen, psikolojik bir durum" şeklinde ifade edilmektedir (Öz, 2004).

Peplau ve Perlman (1982)'a göre yalnızlık, bir kişinin diğer bireylerin arzuladığı ilişki ile yaşadığı ilişki arasındaki uyumsuzluk sonucunda oluşan, istenmeyen öznel bir psikolojik durumdur.

Weiss (1973) yalnızlı̆̆ı, duygusal ve sosyal olmak üzere iki başlıkta incelemiştir. Sosyal yalnızlık, algılanan sosyal ilişkideki yetersizlik ve kişinin çevresiyle birlikte olan etkinlikleri paylaşmada kendisini grubun, olayın ya da etkinliğin bir parçası olarak hissetmemesidir. Duygusal yalnızlık ise, kişinin 
başka bir kişiye karşı kendini yakın olarak algılamayıp uzak görmesi ve kabul edilmediğini hissetmesidir.

Birçok izole birey sosyal kaynaklarla bağlantısını yitirmesine rağmen kendisini yalnız hissetmezken, toplumla iç içe olan bireyler kalabalık içerisinde yalnızlı̆̆ı yaşayabilir (Mullins ve McNicholas, 1987; Genç ve Dalkılıç, 2013). Sosyal izolasyon, kabul edilebilir bir sosyal ağın eksikliğinden kaynaklanır ve bireyin sosyal ortama katılma istekliliği devam edebilir. Ancak bu kendi kendine eğlenebilen ve verimli zaman geçirebilen, sosyal hayata uyum sağlayan, başarılı yaşlanma bilincinde olan eğitimli yaşlılarda negatif bir durum olarak değerlendirilmeyebilir (Mullins ve McNicholas, 1987; Danış, 2007).

Yapılan bir çalışmada fiziksel sağlığın kötüleşmesinin ruhsal hastalıkların, moral düşüklüğünün, bir bakıcıya gereksinim duymanın, coğrafi lokasyonun, iletişim ve ulaşımda yaşanan zorlukların sosyal izolasyona ve yalnızlığa sebep olan faktörler arasında olduğu belirlenmiştir (Edelbrock, Buys, Creasey, ve Broe, 2001). Yaşlılık döneminde izolasyonun bu denli yoğun görülmesinin ve yalnızlık duygusu hissetmelerinin sebeplerinden biri yaşlı bireylerin yalnız yaşamak zorunda kalması, çocuklarının uzakta olması ya da yetişkin evlatlarının yanında çok stresli bir yaşam sürmesidir (Kurt, 2008). Yetersiz sosyal ve duygusal bağ kurma yaşlılarda yalnızlık duygusunun daha fazla hissedilmesine neden olmaktadır (Çam, Atay, ve Işıklı, 2018). Huzuevinde 144 yaşı birey ile yapılan bir araştırmada sosyal ilişkilerdeki azalmanın yalnızlığ 1 artırdığı ve yaşlıların \%46.6'sının yalnız kalmamak için huzurevine geldiği belirtilmektedir (Kahraman, Zincir, Erten, ve Özkan, 2011). Yapılan bir meta analiz çalışmasına göre, kısıtlı ya da tatmin edici olmayan sosyal ilişkileri olan yaşlıların mortalite riski, güçlü sosyal ilişkileri olan kişilere göre daha yüksek olduğu sonucuna ulaşılmıştır (Valtorta, Kanaan, Gilbody, Ronzi, ve Hanratty, 2016). Mortalite artışını etkileyen bir diğer faktörün, yaşlı bireyde ruhsal ve zihinsel yapının desteklenmemesi, buna bağlı benlik saygisında azalma ve intihar düşüncelerinde artma olduğu belirtilmektedir (Simon, Chang, Zhang, Ruan, ve Dong, 2014). Başka bir meta-analiz çalışmasında ise normal bireylerle kıyaslandığında ölüm oranındaki artış yalnızlık için yaklaşık \%26, sosyal izolasyon için \%29 ve tek başına yaşayanlar için \%32 olarak belirtilmiştir (Holt-Lunstad, Smith, Baker, Harris, ve Stephenson, 2015). Yapılan çalışmalarda yalnızlık ile sosyal izolasyonun kalp ve damar hastalığı gelişimini ve felç riskini de arttırdığı tespit edilmiştir (Boden- 
Albala, Litwak, Elkind, Rundek, ve Sacco, 2005; Patterson ve Veenstra, 2010; Valtorta vd., 2016).

\section{Yaşlılarn Sosyal İzolasyon ve Yalnızlık Yaşamasına Neden Olan Faktörler}

Yaşlılar yetişkinlere göre yalnızlık ve sosyal izolasyon yaşamaya daha yatkın bireylerdir.

Yaşlı bireylerde yalnızlık duygusunun yaşanmasına sebep olan bireysel faktörler; eş ya da arkadaş kaybı, emeklilik, evinde yaşamını sürdürememe, kronik hastalıklar, duyusal yitimler, fiziksel sinırlılıklar ve başkalarına bağımlı olma algısı şeklinde sıralanabilir (Akdemir, 2003). Ayrıca kentsel ya da kırsal alanda yaşama durumu, sosyal destek sistemlerinin azlığı (Karadakovan, 2014; Erol vd., 2016), yetersiz sosyal, kültürel ve ekonomik koşullar (Danış, 2007), rollerde değişim gibi çevresel faktörler sıralanabilir.

Birçok yaşlı birey, toplumda üretici konumdan tüketici konumuna geçerek, önceki rollerini yerine getirememektedir (Öz, 2004). Kentleşmenin artması, çekirdek aile yapısına geçiş, çocuklar ile yaşanan sorunlar nedeniyle ayrı yaşama, huzurevine yerleşerek primer sosyal destek kaynaklarından uzaklaşan yaşlıların sosyal çevreleriyle yeterli samimi ve sıcak ilişki geliştirememeleri yalnız hissetmelerine, benlik algılarını olumsuz yönde etkileyerek bazı psikolojik sıkıntılar yaşamalarına neden olabilir (Kerem, Meriç, Kırdı, ve Cavlak, 2001; Gökler ve Aydın, 2011).

Yaşlıda psikososyal sorunlara sebep olan faktörlerden biri de kronik hastalıkların varlığıdır. Hastalıkla birlikte zamanla yaşlı bireyin sosyal aktivitelerinde azalma ve bundan sonraki hayatını var olan hastalığıyla geçireceği düşüncesi, yaşlıda yetersizlik duygusu oluşturmakta ve yalnızlık hissi ile birlikte sosyal izolasyon yaşamasına sebep olmaktadır (Khorsıd ve Arslan, 2006; Polat ve Kahraman, 2013).

\section{Yaşlılarda Yalnızlı̆̆ın Belirtileri}

- Beslenme alışkanlığında farklılaşma, kilo alma ya da verme,

- Uyku örüntüsünde bozulmalar, aşırı uyuma ya da uykusuzluk,

- Önemsizlik duygusu,

- Sırt, bel, bacak vb. bölgelerde oluşan psikosomatik ağrılar, 
- Pek bir anlam ifade etmeyen, amaçsız tek başına yapılan faaliyetlerde artış (sürekli alışveriş yapma, amaçsız uzun süre televizyon seyretme),

- Alkol ve ilaç kullanımında artış,

- Öz kıyım girişimleri,

- Postür değişimleri (Omuzlar düşmüş, dudaklar aşağı kıvrılmış, yavaş adımlarla acı çekermiş gibi yürüme vb),

- Umutsuzluk,

- Yaşamdan çekilmek, sessizleşmek, ilgisiz olmak ve amaçsız kalmaktır (Öz, 2004).

Oluşan yalnızlık hissi, daha öncede belirtildiği gibi yaşlı bireylerde fiziksel ve ruhsal sağlık problemlerinin oluşmasında önemli rol oynayabilir. İnsanın psikolojik anlamda mutluluğunu, iyilik halini ve uyum yeteneğini etkileyebilir (Ardahan, 2010; Kahraman, vd 2011; Püllüm ve Akyıl, 2017). Dolayısıyla yaşlının yaşamdan doyum alması bozularak yaşantısı dayanılmaz hale gelebilmektedir (Altuğ vd., 2009; Erol vd., 2016).

\section{Yaşlılarda Sosyal İzolasyon ve Yalnızlığın Sonuçları}

Sosyal izolasyon ve yalnızlık duygularının yol açtığı olumsuz etkileri bireysel ve sosyal olarak iki başlıkta değerlendirebiliriz:

Bireysel Açıdan Etkisi: Yaşlanan birey, yetenekleri ve yeterlilikleri azaldıkça kendisine gösterilen tavır ve davranışlarda farklılık hissedecek, yaşı nedeniyle gelişen alg1 ve yargılama süreçleri neticesinde kendisini daha fazla yalnız hissedecektir. Yalnızlık sağlığın bozulmasına ve yaşam kalitesinin azalmasina neden olan bir duygudur. Bireyin yaşı, cinsiyeti, medeni durumu, eğitim düzeyi, içinde bulunduğu kültür, yaşadığı bölge, kişilik özellikleri, yalnız ya da eş ve çocuklarıyla birlikte yaşama durumu, sağlık durumu yalnızlık duygusunu önemli ölçüde etkileyen faktörlerdir (Demirtaş, 2015; Çam, Atay, ve Işıkl1, 2018).

Sosyal bir varlık olan insan kişilerarası iletişimde bulunmadığı zaman, yaşamında güven duyabileceği önemli kaynaklarını kaybedecektir (Kalınkara, 2016). Ortaya çıkan bu durumlar yaşlının başkalarına bağımlı hale gelmesine, 
yetersizlik duygusu yaşamasına, benlik saygisının azalmasına neden olmaktadır. Yetersizlik duygusu yaşayan yaşlılarda azalan benlik saygisı depresyona ve intihar girişimine neden olabilmektedir (Singh ve Misra, 2009; Demirtaş, 2015; Kalınkara, 2016). Aynı zamanda yaşlının diğerlerine göre daha fazla ruhsal hastalıklar, koroner kalp hastalığı, felç geçirme riski, kan basıncında artış, stres ve kalitesiz uyku gibi problemler yaşamasına sebep olacaktır (Olufemi, 2017; Yu, Steptoe, Niu, Ku, ve Chen, 2018). Bu nedenle, arkadaşlarımızla ve ailelerimizle iletişim halinde olmak, sosyal bağlantılarımızı güçlendirmek ve sayısını artırmak refahımız için faydalı olacaktır (Olufemi, 2017).

Sosyal ilişkiler, insan refahının ayrılmaz bir parçasıdır ve sağlığın korunmasında kritik rol oynamaktadır (Holt-Lunstad ve Smith, 2010). Pek çok araştırma yalnızlık ve sosyal izolasyon ile ruhsal sağlık, intihar, erken ölüm, depresyon, kardiyovasküler hastalıklar, sigara kullanımı, diyabet tanısı, demans gibi bir çok değişken ile arasında pozitif bir ilişki olduğunu belirtmektedir (Fratiglioni ve Paillard, 2004; Singh ve Misra, 2009; Shankar, Hamer, McMunn, ve Steptoe, 2013; Cacioppo ve Cacioppo, 2014). Yapılan çalışmalara bakıldığında sosyal ağ ve ilişkili faktörlerin desteklenmesi yaşlıların duygudurumunu olumlu yönde etkileyebilecek ve bu da yaşlı insanların yaşam kalitesini ve ruhsal sağlığını etkileyecektir.

Yapılan çalışmalar aile, arkadaş ve bağlı bulunduğu gruplar ile tatmin edici ilişkileri olan insanların daha mutlu olduğunu, daha az sağlık sorunu yaşadıklarını ve daha uzun yaşadıklarını bildirmektedir. Aksine, sosyal ağın azlığ 1 ise, depresyon ve bilişsel fonksiyonlarda gerilemelerle ilişkilendirilmiştir (Harward Medical School, 2010). Sosyal izolasyon veya yalnızlık bildiren yaşlı bireylerin, 4 yıl sonra daha zayıf bilişsel fonksiyonlara sahip olduğu bildirilmektedir (Shankar vd., 2013; Cacioppo ve Cacioppo, 2014). Yaşlılarda sosyal izolasyon ve yalnızlık, zayıf bilişsel işleyiş için değiştirilebilir bir risk faktörü olarak görülmektedir. Risk altındaki yaşlı bireylerin bilişsel fonksiyonlarının korunmasına yönelik olarak sosyal ortamına gereken önemin verilmesi gerektiği belirtilmektedir (Cacioppo ve Cacioppo, 2014).

Sosyal Açıdan Etkisi: Bir toplumun uyumunu ve dayanışmasını olumsuz yönde etkileyen önemli değişkenlerden biri de sosyal yaşama katılmayan/katılamayan çok sayıdaki yaşlılardır (Kalınkara, 2016). 
Yaşlılık döneminde normal faaliyetleri yerine getirmede yaşanan zorluklar yaşlının barınma, eğitim, ekonomi, sosyo-kültürel, toplumsal, sağlık ve politika alanları gibi birçok alanda güçlük yaşamasına neden olmaktadır (Genç ve Dalkılıç, 2013; Görgün Baran, 2016; Çunkuş, Yiğitoğlu, ve Akbaş, 2019).

Yaşlı bireylerin, girdiği sosyal etkileşimlerde yetersizlik duygusunu algılaması, rahat ve güvenilir ortamları bulamaması ve çevresiyle oluşturduğu paylaşımlarda kendisini grubun bir üyesi olarak hissedememesi sosyal yalnızlı̆̆ı oluşturmada önemli etmenlerdir (Weis, 1973; Çam, Atay, ve Işıklı, 2018). Bununla birlikte kentleşme, kadınların iş hayatında aktif yer alması, geniş aile yapısından çekirdek aile yapısına dönüşüm, maddi problemler, kuşaklar arası iletişim problemleri, gençlerin yaşlıya karşı oluşturdukları bakış açısı, hastalıkların varlığı ve buna bağlı gelişen bağımlılık yaşlıların evde bakımını olumsuz yönde etkilemiştir (Ardahan, 2010). Toplumdan izole olan yaşlı, kendi çevresinden destek alamayınca, daha iyi bir bakım için ekonomik bir güç gerektiren resmi desteğe yönelim göstermektedir (Kalınkara, 2016). Yaşlı bireylerin evinden ayrılarak huzurevlerine yerleşmeleri yaşamlarında önemli bir çevresel değişim yaratmaktadır. (Gökler ve Aydın, 2011). Aile ve arkadaş ortamından uzak bir yaşam, yeni bireylerle samimi ve sıcak bir ilişki kuramama, yeterli sosyal desteğin olmayışı yaşlıların stresle baş etmelerini güçleştirerek psikolojik sorunlar yaşamasına sebep olmaktadır. Gün geçtikçe kişilerarası ilişkileri, sosyal aktivitelere katılımı ve toplumsal yapı içerisindeki yaşantıları azalarak bireyi fiziksel, sosyal ve ruhsal yönden etkilemektedir (Softa, 2015). Bu nedenle yaşlı bireyin bu dönemde desteklenmesi, ihtiyaç duyduğu çevresi ile kaliteli ve doyum alacağı bir şekilde vakit geçirmesi ve toplumdaki yaşlılığa ilişkin olumsuz bakış açısının değiştirilmesi önem taşımaktadır.

\section{Yaşlılarda Sosyal İzolasyonun ve Yalnızlı̆̆ın Azaltılmasında Sosyal Desteğin Önemi}

Eş, aile ve arkadaşlardan oluşan sosyal destek kaynakları, yaşlıların fiziksel ve psikolojik sağlamlılığını pozitif yönde etkileyerek, onların sevgi, benlik saygısı ve aidiyet duygusu gibi temel sosyal ihtiyaçlarını karşılamaktadır (Altıparmak, 2009). Sosyal desteğin azalması yaşlılarda yalnızlık duygusunun artmasına, yaşam doyumunun azalmasına ve dolayısıyla bireyin beden ve 
mental yönden iyilik halinin bozulmasına neden olmaktadır (Poulin, Deng, Ingersoll, Witt, ve Swain, 2012; Wan Mohd Azam vd., 2013; Kapıkıran, 2016). Sosyal destek sistemi, yaşlılarda mortalite riskini azaltarak yarar sağlamakta ve önemli bir iyileşme aracı olarak kabul edilmektedir (Dhar, 2001).

İyi bir sosyal destek ağının geliştirilmesi yaşlının yalnızlık hissini azaltarak istenmeyen durumların yaşanmasını önleyecek ve yaşam doyumunun artıracaktır. Yaşadığı ortamda sevgi ve saygı gören yaşlı bireyin yaşamla olan bağı güçlenecek ve spiritüel alandaki mutluluğu yaşayacaktır (Öz, 2004). Akkaya (2015)'nın yaptığı çalışmada hastalarda yalnızlığın arttıkça sosyal desteğin azaldığını ve yaşam kalitesinin düştügüünü, sosyal destek arttıkça ise yaşam kalitesinin yükseldiğini belirtmiştir. Kapıkıran (2016)'nın 65-92 yaşları arasındaki yaşlıları incelediği çalışmasında eşiyle birlikte yaşayan ve eşi olmayıp çocukları ile yaşayan yaşlıların, boşanmış ve eşi ölmüş yaşlılara göre yaşam doyumu puan ortalamalarının daha yüksek olduğunu saptamıştır. Tanskanen ve Anttila (2016) yaptığı çalışmada; kısıtlı ya da tatmin edici olmayan sosyal ilişkiler yaşayan yaşlıların mortalite riskinin, güçlü sosyal ilişkileri olan kişilere göre daha yüksek olduğunu belirmektedir.

Yaşlılara sosyal desteğin sağlandığı önemli sosyal ortamlardan biri de yaşanan semt ve mahallelerdir. Oturulan çevredeki bakkal, manav, mağazalar, oyun alanları, sosyal aktivite ve kültür merkezleri, parklar vb. yaşlıların kimliğini var etmede fırsatların sunulduğu ve önemli katkıların sağlandığı birimlerdir (Kalınkara, 2016). Yaşlı birey ailesinden, arkadaşlarından ve sosyal çevresinden almış olduğu bu destek ile sağlıklı yaşam biçimi davranışlarını ve stresle baş etme durumlarını olumlu yönde geliştirmiş olacaktır (Polat ve Kahraman, 2013).

\section{Yaşlılarda Sosyal İzolasyon ve Yalnızlıkla Baş Etmede Hemşirenin Rolï}

Bireyin yaşlılık dönemini kabullenebilmesi için kişilerarası ilişkilerin sürdürülmesi, iyi ve kaliteli bir bakım alması büyük önem taşımaktadır (Gökler ve Aydın, 2011). Yalnızlık duygusunun kabullenilmesi, yalnızlıkla baş etmede ilk basamaktır. Yalnızlıkla baş etmenin yolu, amaçlı ve yaratıcı olmakta yatmaktadır. Zamanı en verimli şekilde etkin kullanmak yalnızlıkta oluşan kısır döngünün aşılmasında önemli yer tutmaktadır (Öz, 2004). Yaşam boyunca 
kurulan dostluklar, arkadaşlıklar ve evlilikler içlerinde üretkenliği barındırıyorsa birey yalnız kalmayacak ve yaşam kalitesi artacaktır (Öz, 2004; Khorshid ve Arslan, 2006).

Yaşlıların entelektüel ve sosyal kaynaklarının yeterli hale getirilmesi, yeni ilişkiler kurmasına ve sosyal bağlantılarını sürdürebilmesine firsat vermektedir (Singh ve Misra, 2009). Yaşlılara yeni deneyimler kazandırmak, fiziksel bir alan sağlamak, bireysel bir yolculuğun hazzını yaşatmak, aktivite seviyesini arttırmak, duygularını olumlu yönde değiştirmek amacıyla, merak uyandırıcı ve katılım isteği yaratan aktivitelerin düzenlenmesi (müze gezileri, yazarlık, çizim, resim, heykel ve kolaj atölyeleri vb.) bu konuda yapılabilecekler arasındadır (Todd, Camic, Lockyer, Thomson, ve Chatterjee, 2017). Psikososyal sağlık dahil olmak üzere toplumların sağlığını iyileştirmede en etkili müdahalelerden biri fiziksel aktiviteyi arttırmaktır (Paterson, Jones, ve Rice, 2007). Yaşılırın günlük yürüyüş yapmaları, ev/bahçe işleri ile uğraşmaları, yüzme, dans gibi sosyal aktivitelere katılmalarının sağlanması ile fiziksel aktivite düzeyleri arttırılabilir (Dünya Sağlık Örgütü, 2016). Robins, Jansons ve Haines (2016) tarafından yapılan 17 çalışmanın değerlendirildiği sistematik derlemede, grupla yapılan fiziksel aktivite müdahalelerinin toplumda yaşayan yaşlı yetişkinler arasındaki sosyal izolasyonu azalttı̆̆ını belirtmişlerdir. Yaşlı bireylerde izolasyon ve olumsuz sonuçlarını azaltmak için pek çok aktivite-egzersiz programı tasarlanmıştır (Coyle ve Dugan, 2012). Yaşlıların yaşadığı merkezlerde uygulanmakta olan bu programlara bazı örnekler: aktif seçim, hergün aktif yaşam, zindelik geliştirme, iyiliği geliştirme, zinde ve güçlü sağlıklı hareketlerle yaşlanmadır (National Council on Aging, 2016). Yaşlıların katılım göstereceği bu deneyimler tüm açılardan bakış açılarını değiştirecek, hem kendilerini hem de çevresindekilere karşı olumlu bir algı yaratacak, duyguların daha rahat ifade etmelerine firsat vererek yalnızlık hissinin daha çok azalmasını sağlayacaktır (Todd vd., 2017).

Her birey, bedensel, kültürel, psikolojik, sosyal çevre ve ailesi ile bir bütündür. Hemşirelerin yaşlı bireyi holistik bakış açısıyla, yalnızlığa ilişkin tepki ve davranışlarını açıklayıcı sorularla bir bütün olarak değerlendirmesi ve sorunlarını ele alması çözüme kavuşmada önem taşımaktadır (Ceyhan, 2005; Townsend, 2016). Çünkü yalnızlık kavramı her insan için öznel bir anlam taşıdığından; yalnızlık mesajları sözel ya da sözel olmayan şekillerde ifade edilebilir. Hemşire yaşlının bulunduğu çeşitli yerlerde (ev ziyaretleri, 
klinik ortamlar, huzurevleri) yaşlının yalnızlığını belirlemeye yönelik terapötik tekniklere uygun sorular sorarak değerlendirmelerde bulunmalıdır (Ceyhan, 2005).

Hemşire yaşlının yalnızlık duygusunu değerlendirirken; Sosyokültürel özelliklerini, sözsüz ve sözel mesajlarını, sosyal etkileşimin niceliğini ve niteliğini, sosyal destek sistemlerini, aile içinde karar vericiliğini, aile ve toplum içindeki görevlerini ve sorumlulukların, hoşnut oldukları ve hoşnut olmadıklarını belirlemeli ve bunlar doğrultusunda hemşirelik sorunlarını belirleyip, hemşirelik girişimlerini planlamalıdır (Öz, 2004).

Topladığı verilerle hemşire olası koşulları dikkatlice gözden geçirir ve yapmış olduğu değerlendirme sonucunda bireyle ilgili bakım hedeflerini oluşturur. İnsan, sağlık, hastalık ve çevre kavramlarını kapsayan birey için en uygun hemşirelik modeline göre girişimlerini planlayarak müdahalelerde bulunur (Gümüş, 2014). Hemşire bakım sürecinde yaşlıyı bakıma dahil etmelidir. Aksi durumda, bireyin alınan kararlara katılmaması, sorunun uzamasına, üretilen çözümlerin işe yaramamasına ve sıkıntının artmasına neden olacaktır (Öz, 2004).

Hemşirelik tanısı olarak ele aldığımız "Sosyal izolasyon" tanısına yönelik yapılacak müdahalelerin amacı hastanın sosyal ağını oluşturan kişilerin ve bir sağlık profesyoneli olan hemşirenin bireye destek olabilmesidir (Khorshıd ve Arslan, 2006). Yakın çevresinden yeterli sosyal destek alamayan yaşlılar resmi desteğe gereksinim duymaya başlayacak ve profesyonel kolaylıklara yönelim gösterecektir (Kalınkara, 2016). Gelinen bu noktada hemşire yardım eden rölünü üstlenerek yaşliya sosyal destek sağlayabilmeli ve sosyal destek kaynaklarını en etkin şekilde kullanmasına öncülük edebilmelidir (Khorshıd ve Arslan, 2006). Yaşlıların yalnızlık hissini gidermeye ve sosyal destek sistemlerini geliştirmeye yönelik hemşirelik girişimleri;

- Yaşlı birey iyi bir şekilde gözlemlenmeli, yalnızlık duygusuna ait belirti ve bulgular değerlendirilmelidir.

- Emekliliğin kendisinin yaşamı üzerinde olası/beklenen etkileri konusunda duygularını ve düşüncelerini ifade etmesi için cesaretlendirilmelidir (Yeteri kadar gelir planlama, işte geçen zamanı azaltıp, daha uzun tatiller planlama, evde işin yerini alacak rutinler planlama, boş zaman aktiviteleri edinme vb), 
- Yaşlı bireylerin topluma aktif katılımını sağlayacak firsatlar değerlendirilir ve kendilerini geliştirmeleri konusunda destek olunur. Yalıtılmış dünyayı genişletme stratejileri oluşturması sağlanır (emeklilik gruplarına katılma, yaşlı bireyler için açlan okullar/üniversitelere gitme, evcil hayvan edinme, yardım gereksinimi olan bireylere yönelme vb. programlardan yararlanma),

- Toplumdaki sosyalizasyon kaynakların tanımasına ve aktif katılımının sağlanmasına danışmanlık edilir,

- Yaşlılık sürecini sağlıklı bir şekilde, rahat ve güvenilir bir ortamda yaşamalarına imkan verecek hizmetler sunulur (yaşliya ya da bakım verene rehberlik ve danışmanlık hizmeti, aile bireyleri ile iletişim konusunda daha samimi ilişkiler yaşamasına yardımcı olma),

- Sosyal kaynaklardan yararlanma ve onları elde etme konusunda gerekli ulaşım hizmetlerine yönlendirme gibi uygulamalar konusunda yardımc olunur (Carpenito, 2012).

\section{Sonuç}

Yaşlıların sosyal izolasyon ve yalnızlık duygularını azaltmaya yönelik günümüz şartlarına uygun çözüm yolları aranmalıdır. Yaşlı bireylerin, kendilerini daha mutlu ve güvende hissettikleri aile üyeleri ile bir arada yaşamaları bu duygularla baş etmede önemli bir destek kaynağı oluşturmaktadır (Öz, 2004). Bu nedenle aile bireylerinin ekonomik, sosyal ve psikolojik yönden desteklenmesi bu sorunun çözümlenmesinde büyük önem taşımaktadır (Kurt, 2008).

Kurumda yaşayan yaşlıların sosyal izolasyon ve yalnızlık duygusunu gidermede ve yaşam kalitesini arttırmada kurum bakımı hizmetlerinin de günün koşullarına göre geliştirilmesi ve huzurevleri dışında yaşlı dayanışma merkezleri, yaşlı klüpleri gibi diğer alternatif bakım hizmetlerinin de düşünülmesi önemlidir (Kurt, 2008). Yaşlılık döneminin geçirildiği bu kurumlarda kadınlar ve erkekler arasında kültürel özelliklerin ve farklılıkların göz önünde bulundurularak sosyal yaşamın ve kişilerarası ilişkilerin güçlendirilmesi gerekmektedir (Kahraman vd., 2011). Yapılacak eğitim ve kültürel gezi programları (Todd vd., 2017), motivasyonlarını artırıcı sosyal aktivite düzenlemeleriyle yaşlılarda yalnızlık duygusu önlenebilir (Kahraman vd., 2011). 
Sonuç olarak, bütüncül bir bakış açısıyla özellikle sosyal izolasyon ve yalnızlık açısından riskli yaşlılar (kurumda yaşayan, eşini kaybeden, sosyal etkileşimde sorun yaşayanlar, ekonomik güçlükler yaşayan, sağlık problemi olanlar) düzenli izlenmeli ve bu grupta çalışan sağlık ekibi tedavi ve bakım programları oluşturmalıdır. Ayrıca yaşlılara kalıcı çözümlerin oluşturulabilmesi için mevcut durumu ortaya çıkarabilecek, yaşlı sorunlarına çözüm için katkı sağlayacak, yaşlı bireylerin sağlıklı ve mutlu yaşamasını sağlayacak multidisipliner araştırmalar yapılmalıdır. 


\section{EXTENDED ABSTRACT}

\section{Social Isolation and Loneliness in Elderly \\ Ebru Akbaş - Gülay Taşdemir Yiğitoğlu - Nesrin Çunkuş \\ Pamukkale University}

In today's world, with the increase in the quality of life, medical and technological developments, decrease of infectious diseases, prolonging life with chronic diseases and decreasing mortality rates in today's world; population of elderly is gradually increasing (Santrock, 2015) The elderly population consists $9.1 \%$ of world's population. In Turkey, elderly population has increased by $16 \%$ in the last five years and exceeded 7 million (TÜIK, 2018). Many social and economic issues arise with this increase (Attanasio ve Pistaferri, 2016). Therefore it is at utmost importance to approach elderliness with all its aspects in mind. Elderliness is an age where changes occur at various levels in biological, psychological, mental and social aspects of life (Townsend, 2016). Decrease in body's functionality and the accompanying chronic diseases cause elders to be more in need of other more emotionally an socially (Beğer ve Yavuzer, 2012; Kislaya, Santos, ve Gil, 2013). Literature on elderliness support that fulfillment in life decreases and and loneliness and social isolation are experienced more often in this age (Kaçan-Softa, Öztürk, Dindaş, ve Göçmen, 2015; Erol, Sezer, Şişman, ve Öztürk, 2016; Kapıkıran, 2016; Kalınkara ve Sarı, 2019).

Social isolation is defined as a situation where a person loses the sense of belonging, cannot connect with other people, has few social contacts and they are not enough to sustain a high quality relationship (Olufemi, 2017). Loneliness is defined as a psychological state which decreases life satisfaction, caused by lack and deprivation of social relationships (Öz, 2004).

Elderly are usually more inclined to experience loneliness and social isolation. Causes for loneliness in elderly are; loss of spouse or a friend, retirement, leaving home, changes in roles, loss of senses, chronic diseases, physical restrains, financial hardships and dependance on others (Akdemir, 2003). In addition to these, enviromental factors such as living situation (urban or rural), lack of social support system (Karadakovan, 2014; Erol vd., 2016), insufficiant social, cultural and economic conditions (Danış, 2007), and changes 
of roles in life may affect loneliness.

- Changes in eating habits, gaining or losing weight,

- Impairment in sleep patterns, hypersomnia or insomnia,

- Feeling of insignificance,

- Psychosomatic pains in back, waist and leg,

- Increase in meaningless activities done individually (constant shopping, watching TV without purpose for too long),

- Increase in alcohol and drugs intake,

- Suicide attempts,

- Changes in posture (shoulders down, frown, walking with small steps as if in pain),

- Hopelessness,

- Withdrawal from life, silence, showing little interest and lack of purpose (Öz, 2004).

Individual Consequences: Elder people start feeling and noticing differences in other people's attitude and behavior towards themselves as their skills and competences decrease gradually. With the developments of their perception and judgement, they feel lonelier. Loneliness is a feeling that causes health problems and decrease in quality of life. Age, gender, marital status, level of education, cultural environment, residential area, personality features, living situation (alone or with family) and health are all important factors to feeling of loneliness (Demirtaş, 2015; Çam, Atay, ve Işıklı, 2018).

Social Consequences: One of the important variables that negatively affect the harmony and solidarity of a society is the elderly who cannot or will not participate in social life (Kalınkara, 2016).

Difficulties in performing normal activities in the old age cause the elderly to have difficulties in many areas such as shelter, education, economy, sociocultural, social, health and policy areas (Genç ve Dalkılıç, 2013; Görgün Baran, 2016; Çunkuş, Yiğitoğlu, ve Akbaş, 2019).

Social support resources, consisting of spouses, families and friends, positively affect the physical and psychological resilience of the elderly and meet their basic social needs such as love, self-esteem and sense of belonging (Altıparmak, 2009). 
The decrease in social support causes an increase in loneliness in the elderly, a decrease in life satisfaction, and therefore a deterioration of the individual's physical and mental well-being (Poulin, Deng, Ingersoll, Witt, ve Swain, 2012; Wan Mohd Azam vd., 2013; Kapıkıran, 2016). The social support system benefits by reducing the risk of mortality in the elderly and is considered an important recovery tool (Dhar, 2001).

Nursing interventions to eliminate the loneliness of the elderly and to develop social support systems are:

- The elderly individual should be well observed, the signs and symptoms of loneliness should be evaluated,

- The elderly individual should be encouraged to express their feelings and thoughts about the possible expected effects of retirement on their life (planning enough income, reducing time spent at work, planning longer vacations, planning routines to replace work at home, getting leisure activities, etc.),

- Opportunities for active participation of elderly individuals to society should be evaluated and supported to improve themselves. It should be ensured that they create strategies to expand the isolated world (joining pension groups, going to schools / universities opened for older individuals, getting pets, turning towards individuals in need of help, etc.),

- Advising the elderly to recognize social opportunities in the community and to ensure their active participation,

- Providing aervices to enable them to experience the aging process in a healthy, comfortable and reliable environment (guidance and counseling services for the elderly or caregivers, helping them to have more intimate relationships with family members),

- Assisting the elderly individual to benefit from social resources and accessing necessary transportation means for obtaining these resources (Carpenito, 2012).

As a result, elderly individuals who are at risk of social isolation and loneliness (those who live in institutions, lost their spouse, have problems in social interaction, have economic difficulties, have health problems) should be monitored regularly from a holistic perspective and the healthcare teams working for this group should establish treatment and care programs. 
In addition, multidisciplinary research should be conducted to reveal the current situation, to contribute to the solution of problems of elderly, to ensure that elderly individuals live healthy and happy in order to create permanent solutions for the elderly.

\section{Kaynakça / References}

Akdemir, N. (2003). Yaşlılık ve sorunları. (N. Akdemir ve L. Birol Eds.). İç Hastalıkları ve Hemşirelik Bakımı içinde (s.170). İstanbul: Vehbi Koç Vakfı SANERC Yayın.

Akkaya, F. (2015). Romatoid artrit hastalarnda yalnızlk, sosyal destek ve yaşam kalitesini etkileyen faktörlerin belirlenmesi. Yayımlanmamış yüksek lisans tezi. Atatürk Üniversitesi, Sağllk Bilimleri Enstitüsü, Erzurum.

Alttparmak, S. (2009). Huzurevinde yaşayan yaşlı bireylerin yaşam doyumu, sosyal destek düzeyleri ve etkileyen faktörler. Firat Üniversitesi Sağlk Bilimleri Tip Dergisi, 23(3), 159-164.

Altuğ, F., Yağcl, N., Kitiş, A., Büker, N. ve Cavlak, U. (2009). Evde yasayan yasl1larda yasam kalitesini etkileyen faktörler. Yaşlı Sorunları Araştırma Dergisi, 2(1), 48-60.

Ardahan, M. (2010). Yaşlllık ve huzurevi. Aile ve Toplum Dergisi, 5(20), 25-32.

Attanasio, O.P, Pistaferri, L. (2016). Consumption inequality. Journal of Economic Perspectives, 30(2), 3-28.

Beğer, T. ve Yavuzer, H. (2012). Yaşlılık ve yaşllık epidemiyolojisi. Klinik Gelişim, 3(25), 1-3.

Boden-Albala, B., Litwak, E., Elkind, M., Rundek, T. ve Sacco, R. (2005). Social isolation and outcomes post stroke. Neurology, 64(11), 1888-92.

Cacioppo, J. T. ve Cacioppo, S. (2014). Older adults reporting social isolation or loneliness show poorer cognitive function 4 years later. Evidence-based nursing, 17(2), 59-60.

Carpenito, L. J. (2002). Hemşirelik Tanıları el kitabı. (F. Erdemir, Çev.). İstanbul: Nobel Tip Kitabevleri., 312-382.

Ceyhan, S. (2005). Kayseri nuh naci yazgan sağ lık ocă̆ı bölgesinde yaşayan 65 yaş ve üstü bireylerin yalnızlı düzeylerinin incelenmesi. Yayımlanmamış yüksek lisans tezi. Erciyes Üniversitesi, Sağlık Bilimleri Enstitüsü, Kayseri.

Coyle, C. E. ve Dugan, E. (2012). Social isolation, loneliness and health among older adults. Journal of aging and health, 24(8), 1346-1363.

Çam, C., Atay, E., Işıklı, B. (2018). Yaşlılarda yalnızlık ve yaşam kalitesi. Türk Dünyası Uygulama ve Araştırma Merkezi Halk Sağlığı Dergisi, 3(2), 50-67. 
Çunkuş, N., Yiğitoğlu, G. T. ve Akbaş, E. (2019). Yaşlılık ve toplumsal dışlanma. Geriatrik Bilimler Dergisi, 2(2), 58-67.

Danış, M. Z. (2007). Yaşlılı, yoksulluk ve yalnızlık. 3 Kasım 2019 tarihinde http://www.gebam.hacettepe.edu.tr/sosyal boyut/yaslilik yoksuluk yanlizlik.pdf adresinden erişildi.

Demirtaş, H. (2015). Yaşllarda üriner inkontinans geriatrik depresyon ve yalnızlık arasindaki ilişkinin incelenmesi. Yayımlanmamış yüksek lisans tezi, Yıldırım Beyazıt Üniversitesi, Sağlık Bilimleri Enstitüsü, Ankara.

Dhar, H. L. (2001). Gender, aging, health and society. J Assoc Physician India, 49, 1012-20.

Dünya Sağlık Örgütü [DSÖ] (2016). Physical activity and older adults. 1 Kasım 2019 tarihinde https://www.who.int/dietphysicalactivity/fact-sheet_olderadults/en/ adresinden erişildi.

Edelbrock, D., Buys, L., Creasey, H. ve Broe, G. A. (2001). Social support, social networks and social isolation: the Sydney older persons' study. Australasian Journal on Ageing, 20(4), 173-8.

Erol, S., Sezer, A., Şişman, F. N. ve Öztürk, S. (2016). Yaşlılarda yalnızlık algısı ve yaşam doyumu. Gümüşhane Üniversitesi Sağllk Bilimleri Dergisi, 5(3), 6069.

Fratiglioni, L., Paillard-Borg, S. ve Winblad, B. (2004). An active and socially integrated lifestyle in late life might protect against dementia. The Lancet Neurology, 3(6), 343-353.

Genç, Y. ve Dalkılıç, P. (2013). Yaşlıların sosyal dişlanma sendromu ve toplumsal beklentileri. The Journal of Academic Social Science Studies International Journal of Social Science-JASSS, 6, 461-482.

Gökler, I. ve Aydın, G. (2011). Huzurevinde yaşayan yaşlıların benlik algılarının yordanmasında sosyo-demografik özellikler ve algılanan sosyal desteğin rolü. Aile ve Toplum Dergisi, 7(24), 69-91.

Görgün Baran, A. (2016). Yaşlılıkta sosyal dışlanmanın toplumsal boyutu. (V. Kalınkara Ed.). Yaşlılık Disiplinlerarası Yaklaşımlar, Sorunlar, Çözümler içinde (s.105-126). Ankara: Nobel Kitabevi.

Gümüş, A. B. (2014). Hemşirelik kuram ve modelleri. (O. Çam ve E. Engin Ed.). Ruh Să̆ Sağ̆lğı ve Hastalkları Hemşireliği: Bakım Sanatı içinde (s.59-84). İstanbul: İstanbul Tip Kitabevi. 
Harvard Medical School. (2010). The health benefits of strong relationship. Harvard Health Publications, USA. 15 Ekim 2019 tarihinde https://www.health.harvard.edu/newsletter_article/the-health-benefits-of-strong-relationships adresinden erişildi.

Holt-Lunstad, J., Smith, T. B. ve Layton, J. B. (2010). Social relationships and mortality risk: a meta-analytic review. PLOS Medicine, 7(7), e1000316.

Holt-Lunstad, J., Smith, T.B, Baker, M., Harris, T., Stephenson, D. (2015). Loneliness and social isolation as risk factors for mortality: a metaanalytic review. Perspectives on Psychological Science, 10(2), 227-37.

Kaçan-Softa, H., Öztürk, A., Dindaş, İ., ve Göçmen, M. (2015). Kastamonu 1no'lu Aile Sağlı̆̆1 Merkezine başvuran yaşlıların yalnızlık düzeyini etkileyen bazı faktörlerin incelenmesi. Yaşlı Sorunları Araştırma Dergisi, 8(2), 88-97.

Kahraman, S., Zincir, H., Erten, Z. K. ve Özkan, F. (2011). Bir huzurevinde yaşlı kadın ve erkeğin ayrı yaşamasının onların yalnızlık ve yaşam doyumuna etkisi. Sosyoloji Araştırmaları Dergisi, 14(2), 1-16.

Kalınkara, V., ve Sarı, İ. (2019). Yaşlılarda sosyal ağ kullanımı ve yalnızlık ilişkisinin belirlenmesi. Yaşlı Sorunları Araştırma Dergisi, 12(1), 8-19.

Kalınkara, V. (2016). Temel gerontoloji yaşlılık bilimi. Ankara: Atlas Basım Yayın.

Kapıkıran, Ş. (2016). Yaşlılarda yalnızlık ile yaşam doyumu arasındaki ilişki: Sosyal desteğin aracılık rolünün sınanması. Yaşlı Sorunları Araştırma Dergisi, 9(1), 13-25.

Karadakovan, A. (2014). Yaşlı sağhı̆̆ı ve bakım. Ankara: Akademisyen Kitabevi.

Kerem, M., Meriç, A., Kırdı, N. ve Cavlak, U. (2001). Ev ortamında ve huzurevinde yaşayan yaşlıların değişik yönlerden değerlendirilmesi. Türk Geriatri Dergisi, 4(3), 106-112.

Kislaya, I., Santos, A.J. ve Gil, A.P. (2013). Co-occurrence of different types of violence in Portuguese elder adults. Comprehensive Psychiatry, 49, 113-120.

Khorshid, L. ve Arslan, G. G. (2006). Hemşirelik ve sosyal desteğin önemi. Dirim, 81(1), 182-188.

Kurt, G. (2008). Türkiye'de yaşlılık olgusuna sosyolojik bir bakış-Sivas il örneği. Yayımlanmamış yüksek lisans tezi, Cumhuriyet Üniversitesi, Sosyal Bilimler Enstitüsü, Sivas.

Kurt, G., Beyaztaş, F. ve Erkol, Z. (2010). Yaşlıların sorunları ve yaşam memnuniyeti. Adli Tip Dergisi, 24(2), 32-39.

Mullins, L. C. ve McNicholas, N. (1987). Loneliness among the elderly: issues and considerations for professionals in aging. Gerontology E Geriatrics Education, 7(1), 55-66. 
Mullins, L. C., Sheppard, H. L. ve Andersson, L. (1991). Loneliness and social isolation in Sweden: Differences in age, sex, labor force status, self-rated health, and income adequacy. Journal of Applied Gerontology, 10(4), 455468.

NCOA-National Council on Aging (2016). Exercise programs that promote senior fitness. 1 Kasım 2019 tarihinde https://www.ncoa.org/center-for-healthyaging/basics-of-evidence-based-programs/physical-activity-programsfor-older-adults/ adresinden erişildi.

Olufemi, O. O. (2017). Social isolation in the elderly; Physical Activity to the Rescue. Dev Disabil, 1(1), DIDD.000502.

Öz, F. (2004). Sağlık alanında temel kavramlar. Ankara: İmaj Basım.

Öz, F. ve Svvift, J. (2002). Yaşamın son evresi: yaşlılık psikososyal açıdan gözden geçirme. Kriz Dergisi, 10(2), 17-28.

Paterson, D. H., Jones, G. R. ve Rice, C. L. (2007). Ageing and physical activity: evidence to develop exercise recommendations for older adults. Applied physiology, nutrition, and metabolism, 32(S2E), S69-S108.

Patterson, A.C., Veenstra, G. (2010). Loneliness and risk of mortality: A longitudinal investigation in Alameda County, California. Social science $\mathcal{E}$ medicine, 71(1), 181-6.

Peplau, L. A., ve Perlman, D. (1982). Perspective on loneliness. (L.A. Peplau \& D. Perlman Eds.). Loneliness: A sourcebook of current theory, reseach and therapy içinde (s.1-18). New York: John Wiley and Sons.

Polat, Ü. ve Kahraman, B.B. (2013). Yaşlı bireylerin sağlıklı yaşam biçimi davranışları ve algılanan sosyal destek arasındaki ilişki. Fırat Tıp Dergisi, 18(4), 213-218.

Poulin, J., Deng, R., Ingersoll, T. S., Witt, H. ve Swain, M. (2012). Perceived family and friend support and the psychological well-being of American and Chinese elderly persons. Journal of cross-cultural gerontology, 27(4), 305317.

Püllüm, E. ve Akyıl, R. Ç. (2017). Loneliness and social isolation among eldely people. Meandros Medical and Dental Journal, 18(3), 158-163.

Robins, L. M., Jansons, P. ve Haines, T. (2016). The impact of physical activity interventions on social isolation among community-dwelling older adults: a systematic review. Research E Reviews: Journal of Nursing and Health Sciences, 2(1), 62-71.

Santrock, J. W. (2015). Yaşam boyu gelişim. (G. Yüksel, Çev.). Ankara: Nobel Akademik Yayıncılık Eğitim Danışmanlık Tic. Limited Şti., 10-56. 
Shankar, A., Hamer, M., McMunn, A. ve Steptoe, A. (2013). Social isolation and loneliness: relationships with cognitive function during 4 years of followup in the English Longitudinal Study of Ageing. Psychosomatic Medicine, 75(2), 161-170.

Simon, M.A., Chang, E-S., Zhang, M., Ruan, J., Dong, X. (2014). The prevalence of loneliness among US Chinese older adults. Journal of aging and health, 26(7), 1172-88.

Singh, A. ve Misra, N. (2009). Loneliness, depression and sociability in old age. Industrial Psychiatry Journal, 18(1), 51-55.

Softa, H. (2015). Evde ve huzurevinde kalan yaşliların fizyolojik, psikolojik ve sosyal yönden incelenmesi. Yaşlı Sorunları Araştırma Dergisi, 8(2), 63-76.

Tanskanen, J. ve Anttila, T. (2016). A prospective study of social isolation, loneliness, and mortality in Finland. American journal of public health, 106(11), 2042-2048.

Todd, C., Camic, P. M., Lockyer, B., Thomson, L. J. ve Chatterjee, H. J. (2017). Museum-based programs for socially isolated older adults: Understanding what works. Health \& Place, 48, 47-55.

Townsend, M. C. (2016). Ruh Sağhı̆̆ı ve Psikiyatri Hemşireliğinin Temelleri Kanıta Dayalı Uygulama Bakım Kavramları. (C. T. Özcan ve G. Nermin, Çeviri Editörleri.). Ankara: Akademisyen Tıp Kitabevi., 717-750.

-Türkiye İstatistik Kurumu [TUIK] (2018). İstatistiklerle yaşlılar, 2018. 03 Mayıs 2020 tarihinde https://hsgm.saglik.gov.tr/depo/birimler/kronik-hastaliklar-engelli-db/hastaliklar/Yasli Sagligi/raporlar istatistikler/TUIK Yasli Istatistik 2018.pdf adresinden erişildi.

Valtorta, N. K., Kanaan, M., Gilbody, S., Ronzi, S. ve Hanratty, B. (2016). Loneliness and social isolation as risk factors for coronary heart disease and stroke: systematic review and meta-analysis of longitudinal observational studies. Heart, 102(13), 1009-1016.

Wan Mohd Azam, W. M. Y., Din, N. C., Ahmad, M., Ghazali, S. E., Ibrahim, N., Said, Z., ..., Maniam, T. (2013). Loneliness and depression among the elderly in an agricultural settlement: Mediating effects of social support. Asia-Pacific Psychiatry, 5(1), 134-139.

Weiss, R. S. (1973). Loneliness: The experience of emotional and social isolation. Cambridge, MA: MIT Press

Wenger, G. C. ve Burholt, V. (2004). Changes in levels of social isolation and loneliness among older people in a rural area: a twenty-year longitudinal study. Canadian Journal on Aging, 23(2), 115-127. 
Yu, B., Steptoe, A., Niu, K., Ku, P. W. ve Chen, L. J. (2018). Prospective associations of social isolation and loneliness with poor sleep quality in older adults. Quality of Life Research, 27(3), 683-691.

\section{Kaynakça Bilgisi / Citation Information}

Akbaş, E., Taşdemir Yiğitoğlu, G. ve Çunkuş, N. (2020). Yaşlllıkta sosyal izolasyon ve yalnızlık OPUS-Uluslararası Toplum Araştırmaları Dergisi , 15(26), 4540-4562. DOI: 10.26466-/opus.648658 